\title{
A dual-modality quantification of scattered radiation from head to female breasts during radiological investigations in a tertiary hospital in Nigeria
}

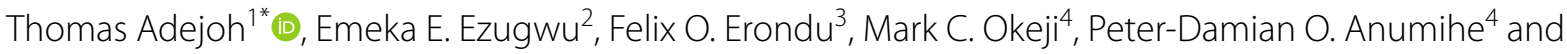
Chijioke O. Asogwa ${ }^{2}$

\begin{abstract}
Background: To quantify the amount of scattered radiation reaching the breasts during $\mathrm{x}$-ray and $\mathrm{CT}$ investigations of the head in order to find appropriate justification for an intended change in practice involving torso shielding.

Results: Scattered radiation from the head reached the breasts in both procedures. The range and mean dose were (CR 1.02-3.61/1.94 $\pm 0.63 \mathrm{mGy}$ ) and (CT 2.20-8.50/3.74 $\pm 2.28 \mathrm{mGy}$ ). Both breasts had enormous dose difference in CR $(72.3 \%)$ and $\mathrm{CT}(51.4 \%)$ which were statistically significant $(p<0.05)$. Correlation of dose with anthropometric parameters gave weak results.

Conclusion: Despite dose mitigation strategies such as software and hardware modifications in radiological modalities, use of anti-scatter grid, appropriate collimation and dose optimization by radiographers, scattered radiation still traveled from the head to the breasts. These were, however, significantly reduced when shielding was applied. For a dose-safe practice, radiographers are urged, in addition to current strategies at mitigating scatters, to adopt torso shielding during examinations involving contiguous anatomies to the breast.
\end{abstract}

Keywords: Scattered radiation, Computed tomography, Computed radiography, Head, X-Ray

\section{Background}

Cancer is induced by different carcinogens including $\mathrm{x}$-ray photons, an ionizing radiation produced by several radiological modalities [1]. Globally, breast cancer is the second leading cause of cancer mortality amongst women, while in Africa specifically, it is the first. The statistics on survival rates also place Africa at a disadvantage. It is reported to be $86 \%$ in developed countries, but $\leq 40 \%$ in sub-Saharan Africa due to late diagnoses [2, $3]$. Despite the carcinogenic tendencies of $x$-ray photons,

\footnotetext{
*Correspondence: thomas.adejoh@futo.edu.ng; adtoms@yahoo.com 1 Department of Radiography, Federal University of Technology, Owerri, Nigeria

Full list of author information is available at the end of the article
}

it is accepted that its benefits far outweigh the risks when dose is as low as reasonably achievable, ALARA [4]. However, while the ALARA principle is effective in reducing the likelihood and severity of deterministic effects of radiation, it appears unreliable in the face of stochastic effects which have no thresholds [1].

Scatters are weakly penetrating, multidirectional secondary radiation photons which contribute to stochastic radiation effect [1]. In addition, they degrade image quality by reducing contrast, thereby impeding diagnosis. They are also enhanced by the size or thickness of tissues, the extent of field of view (FOV) and the $x$-ray energy [2]. The breast is one of the radiosensitive organs, and its protection is recommended during radiography procedures. The tissue weighting factor for 
breast is higher for females than for males and higher for younger females than for older ones, further justifying the need for shielding from scatters, especially in the feminine gender [5]. Scatters are generally mitigated by hardware and software modifications [6], antiscatter grids [2], appropriate beam collimation [7] and dose optimization [1].

Despite these strategies, medical imaging continues to witness scatters in daily practice [6], due to increasing demand for investigations involving ionizing radiation-producing modalities [8]. Head $x$-ray [1] and head CT investigations are anatomical regions with a high throughput in medical imaging. Due to high anatomical density, multiple surrounding structures and higher exposure settings to generate optimum image, the tendency to induce scattered radiation is high during examinations involving the head [6]. To mitigate the impact of these undesirable radiation from this contiguous anatomy to the breast, apparel shielding of the torso is now being recommended and practised $[6,9$, $10]$.

These evidence-based recommendations are, however, not yet implemented in our facility, a regional referral hospital. Due to the strong influence wielded by this facility, implementing a policy change is likely to have a bandwagon effect on numerous feeder facilities who emulate her practice standards, and perhaps, in contiguous geopolitical zones, whose personnel often visited for update courses. This work is an attempt to add to the body of knowledge on the subject matter in the country generally and to specifically present empirical evidence to policy makers in our facility for a paradigm shift in practice.

\section{Methods}

\section{Ethical considerations}

This was a hospital-based, dual-modality, prospective and cross-sectional work undertaken between November and December 2019 at the radiology department of a foremost regional teaching hospital. It involved affixing portable, radioluscent thermoluminescent dosimeters (TLD) on the breasts of adult female patients during $\mathrm{x}$-ray and CT examinations of the head to quantify the amount of scattered radiation reaching the breasts. Ethical approval for the CT component was obtained from the institutional Research Ethics Committee, while approval for the $\mathrm{x}$-ray component was obtained from a neighbouring university ethical subcommittee. Hospital patients were enlisted for the work and they gave informed, signed consent. To guarantee confidentiality, only initials of their name was written in data collection sheet. The TLDs were also numbered and did not indicate name of subjects.

\section{Equipment}

The radiology department had two similar static $\mathrm{x}$-ray machines which were engaged in the work. The machine was General Electrics (GE), silhouette VR, high frequency, 3-phase, static $\mathrm{x}$-ray machines with maximum rating of $140 \mathrm{kVp}$ (tube potential), $600 \mathrm{~mA}$ (tube current) and $2.7 \mathrm{~mm} \mathrm{Al}$ (total filtration). It was manufactured in 2003 and installed in 2012. Within that time frame, it underwent several preventive and restorative maintenance, as well as re-calibrations. The machine had undercouch and erect potter-bucky detector trays incorporated with it [1]. It had full functionality as at the time of the work and had quarterly quality control checks from two dedicated hospital-based engineers. Other equipment and accessories were a computed radiography digitizer (model CR 12-x) (by Agfa healthcare Belgium) produced in December 2013. Detectors were a $25 \mathrm{~cm} \times 30 \mathrm{~cm}$ $\left(10^{\prime \prime} \times 12^{\prime \prime}\right)$ and $35 \mathrm{~cm} \times 43 \mathrm{~cm}\left(14^{\prime \prime} \times 17^{\prime \prime}\right)$ standard photostimulable phosphor imaging plates (model CR MD4.0T General) also manufactured by Agfa Healthcare Germany.

The CT scanner used was also a GE product. It was GE Brightspeed, 4 slice scanner manufactured in 2007 and installed in the centre in 2012. Maximum technical imaging parameters were $140 \mathrm{kVp}$ (tube potential), 350 (tube current), $4 \mathrm{~s}$ (gantry rotation time) and $85 \mathrm{~cm}$ (gantry aperture diameter). It had capabilities for axial and helical scan modes while cine mode was deactivated for the sake of minimizing dose. Calibration was done daily by radiographers using installed calibration software, while engineers carried out quarterly preventive maintenance and quality control.

Scattered radiation was quantified with thermoluminescent dosimeter chips (TLD-100 LiF: Mg, Ti) which had multidirectional energy response. They were acquired, calibrated, annealed and transported from one of the two regional dosimetric centres in the country. Due to cost, only two hundred of those chips were used. To shield them from background radiation, they were enclosed in small, black radiolucent polythene sachets. They were used with that additional enclosure during the procedure.

\section{Subject selection}

Subjects qualified for inclusion if they were ambulant, not on drip infusion or oxygen mask, not gravid as read from request cards and confirmed by them, no evidence of mastectomy, were aged $\geq 18$ years, fell within a weight range of $60-90 \mathrm{~kg}$ in order to filter off outliers like asthenic and hypersthenic body shapes, had a visible neck that separated head from thoracic region, nondrooping breasts and signed a consent form. Although 
adult gynaecomastic cases were qualified for inclusion, none was encountered within the study period. Furthermore, patients were either for $\mathrm{x}$-ray or $\mathrm{CT}$ and not both. So, investigations were carried out in separate diagnostic suites within the department and within the same period. For each modality, only fifty patients were enlisted.

\section{Procedure}

Anthropometric parameters were first obtained. Age was adopted from request cards that came from referring physicians. Gender that was not indicated on request cards was assumed from appearance since culturally, there were gender-specific appearances in the locality. Weight $(\mathrm{kg})$ and height $(\mathrm{m})$ were measured with balanced beam scale with an incorporated adjustable height rule. Both weight and height were read to the nearest $0.5 \mathrm{~kg}$ and $0.01 \mathrm{~m}(1 \mathrm{~cm})$, respectively. Body mass index $(\mathrm{kg} /$ $\mathrm{m}^{2}$ ) was calculated as weight divided by height. Information about $\mathrm{x}$-ray machine and CT scanners was obtained from labels on the machines themselves, while imaging protocols were obtained from control consoles during procedures.

For CT scan of the head, some aspects of the method of Sidi et al. [6] were adopted. Each breast had a TLD chip affixed at its mid-craniocaudal point and held in place by transparent adhesive tapes. In addition, a $30 \times 30 \mathrm{~cm}$ gonad shield with $0.35 \mathrm{~mm}$ lead equivalent was used to shield the left TLD cum breast all through the investigations. This was with a view to compare scatters to both breasts. Computed tomography procedure was carried out by radiographers at the centre according to standard protocols. Subjects were positioned for the CT examination supine, with canthomeatal line (CML) at $90^{\circ}$ to headrest and with an imputed azimuth of $90^{\circ}$ and $180^{\circ}$ for lateral and postero-anterior (PA) scout images. Axial $(x$-axis) centring beam on CT gantry intersected both meatuses, diverged slightly and emerged at infra-orbital margin. The TLDs needed stationary tubes for maximum quantum detection efficiency. Therefore, only scout images in PA and lateral projections with stationary tubes were involved. Popular CT protocol is one in which scout images are generated with the least exposure parameters. In keeping with that ideal, subjects were scanned with $80 \mathrm{kVp}, 10 \mathrm{~mA}$, but with tissue range of $140-250 \mathrm{~mm}$ depending on clinical indication.

For computed radiography of the head, subjects were examined either erect or supine according to standard radiographic procedure. This involved using a potterbucky detector tray or a detector with a stationary grid manually attached. Subjects were positioned for posteroanterior (PA) and lateral views, with canthomeatal line (CML) being perpendicular (PA projection) or parallel (lateral projection) to the horizontal line of the detector tray, respectively. Upper limbs were extended from field of view (FOV) of radiation and employed for stability as well. Exposure parameters were $90-100 \mathrm{~cm}$ focus-detector-distance (FDD), variable tube current $(\mathrm{mA} / \mathrm{mAs})$ and tube potential $(\mathrm{kVp})$ depending on body habitus. The TLD chips were affixed similar to the method used in CT. After scout projections in CT, and PA and lateral projections in CR, the TLD chips were carefully retrieved, packed and then sent for reading at the centre where they were initially acquired.

\section{Data analysis}

Data were analysed with statistical packages for social sciences, version 20.0 (SPSS Incorporated, Chicago, Illinois, USA). Descriptive statistical tools of frequency, mean and mode were employed to give a summary of machine and subjects' parameters and dose outputs. Inferential statistical tools were also employed for analysis. A paired-sample $t$ test was used to test for statistically significant difference in mean absorbed dose by both breasts while Pearson correlation analysis was used to test the strength of relationship between dose and biometric parameters. In the $T$ test, difference found justified the necessity for torso shielding during radiographic examinations of contiguous anatomical regions. Level of significance was set at $p \leq 0.05$.

\section{Results}

A comparative barchart of exposure parameters between $\mathrm{CR}$ and $\mathrm{CT}$ is shown in Fig. 1. Computed radiography had higher values all through except in tube potential $(\mathrm{kVp})$. Machine technical parameters are displayed in Table 1. General Electrics (GE) modalities which were manufactured and installed between 2003 and 2012 were used. Range of exposure parameters available for imaging are also displayed. As shown in Table 2, subjects were aged 19-54 (CR) and 23-55 (CT) and were fairly obese (CR: $34.02 \pm 10.04 \mathrm{~kg} / \mathrm{m}^{2}$; CT

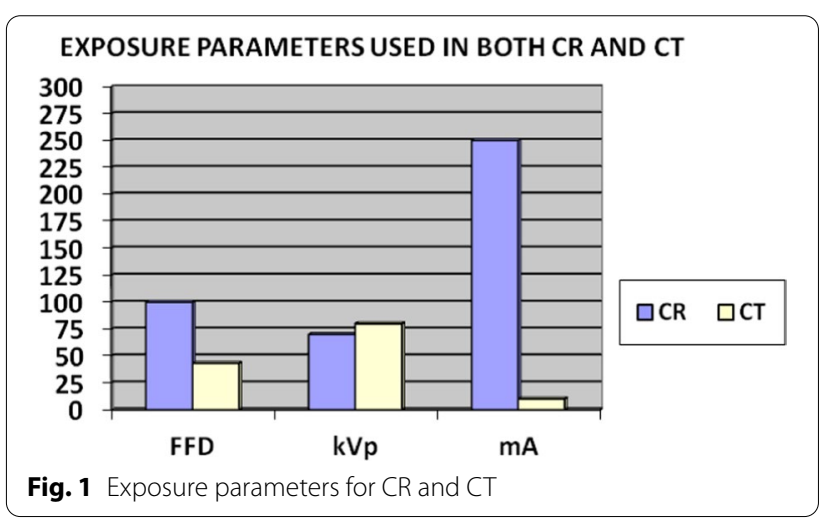


Table 1 X-ray machine and CT scanner properties

\begin{tabular}{lll}
\hline Parameters & CR & CT \\
\hline Model & GE silhouette VR & GE Brightspeed, 4 slice \\
Size & Static/floor mounted & Bulky/fixed \\
Manufactured & 2003 & 2007 \\
Installation & 2012 & 2012 \\
Tube current (mA), range & $10-600$ & $10-350$ \\
Tube potential (kVp), range & $40-150$ & $80,100,120,140$ \\
Exposure time in CR (s) and gantry rotation time in CT (s), range & $0.001-6.3$ & $0.75-4$ \\
Minimum beam filter thickness & 2.7 mmAl & Not known \\
Collimation & Available/perimeter & Available/slice thickness \\
Gantry aperture diameter (cm) & Not applicable & 85 \\
Detectors & Detachable/PSP plates & Inherent \\
Image viewing & On-screen and film & On-screen and film \\
Quality control & Restorative maintenance & Preventive maintenance \\
\hline
\end{tabular}

Table 2 Descriptive statistics of anthropotechnical parameters

\begin{tabular}{|c|c|c|c|c|c|c|c|c|}
\hline \multirow[t]{2}{*}{ S/No. } & \multicolumn{4}{|l|}{ X-Ray (CR) } & \multicolumn{4}{|l|}{ X-Ray (CT) } \\
\hline & Variable $(n=50)$ & Range & Mode & Mean \pm SD & Variable $(n=50)$ & Range & Mode & Mean \pm SD \\
\hline 1. & Age (years) & $19-54$ & 32 & $34.30 \pm 8.02$ & Age (years) & $23-55$ & 35 & $37.18 \pm 7.10$ \\
\hline 2. & Weight (kg) & $60-90$ & 72 & $84.13 \pm 22.02$ & Weight (kg) & $60-90$ & 70 & $82.32 \pm 14.00$ \\
\hline 3. & Height (m) & $1.54-1.82$ & 1.68 & $1.65 \pm 0.30$ & Height (m) & $1.56-1.78$ & 1.65 & $1.64 \pm 0.45$ \\
\hline 4. & $\mathrm{BMI}\left(\mathrm{kg} / \mathrm{m}^{2}\right)$ & $19.6-55.2$ & 28.30 & $34.02 \pm 10.04$ & $\mathrm{BMI}\left(\mathrm{kg} / \mathrm{m}^{2}\right)$ & $18.8-52.2$ & 26.40 & $30.60 \pm 8.20$ \\
\hline 5. & kVp PA & $75-80$ & 70 & & kVp PA & 80 & 80 & \\
\hline 6. & kVp Lat & $70-75$ & 70 & & kVp Lat & 80 & 80 & \\
\hline 7. & mA PA & $250-300$ & 250 & & mA PA & 10 & 10 & \\
\hline 8. & mA Lat & $250-300$ & 250 & & mA Lat & 10 & 10 & \\
\hline 9. & mAs PA & $15-35$ & 18 & & mAs PA & NS & NS & \\
\hline 10. & mAs Lat & $35-80$ & 15 & & mAs Lat & NS & NS & \\
\hline
\end{tabular}

NS not shown (on monitor)

$30.60 \pm 8.20 \mathrm{~kg} / \mathrm{m}^{2}$ ). A summary of scattered radiation to the breasts is given in Table 3 . The range and mean dose were CR: $1.02-3.61 / 1.94 \pm 0.63 \mathrm{mGy}$ and CT: 2.20 $8.50 / 3.74 \pm 2.28 \mathrm{mGy}$. Both breasts had huge dose difference in CR (72.3\%) and CT (51.4\%). There was enormous reduction in dose between unshielded and shielded breasts in CT (113\%) and CR (32.2\%), and these were statistically significant $(p<0.05)$. Correlation of dose with anthropometric parameters gave weak results.

\section{Discussion}

Contiguous radiosensitive organs receive low-dose irradiation often referred to as scattered radiation during radiographic examinations. This irradiation tends to increase the risk to cancer in exposed persons and gene mutation in descendants of exposed persons $[1,6]$. To reduce or prevent scatter to the breasts, apparel shielding has been recommended $[1,6,11]$. This work was an attempt to provide further evidence to consolidate the recommendations in order to have a paradigm shift in current practice at our facility where apparel shielding for patients is not yet being implemented. The questions the work attempted to answer were whether scattered radiation from the head still reached the breasts despite antiscatter strategies by radiographers. In addition, the work sought to know the quantity of scattered radiation that may reach the breast. It was equally desirable to investigate the influence of a one-sided breast shielding on the scattered radiation dose. All these were investigated in both computed radiography (CR) and computed tomography $(\mathrm{CT})$ which were the most common $\mathrm{x}$-ray-producing modalities in medical imaging at the facility.

Findings revealed that scattered radiation indeed reached the breast from both $\mathrm{CR}$ and $\mathrm{CT}$. Left (shielded) and right (unshielded) breasts received a 
Table 3 Dose characteristics in the population

\begin{tabular}{|c|c|c|c|c|c|c|c|c|c|c|c|c|}
\hline \multicolumn{5}{|c|}{ X-Ray (CR); Absorbed dose $(n=50)$} & \multicolumn{8}{|c|}{ X-Ray (CT); Absorbed dose $(n=50)$} \\
\hline \multirow{2}{*}{$\begin{array}{l}\begin{array}{l}\text { Absorbed dose } \\
(\boldsymbol{n}=\mathbf{5 0}) \text { Parameter }\end{array} \\
\begin{array}{l}\text { Right breast/unshielded } \\
(\mathrm{mGy})\end{array}\end{array}$} & Range & \multicolumn{2}{|c|}{ Mean \pm SD } & Mode & \multicolumn{3}{|c|}{$\begin{array}{l}\text { Absorbed dose } \\
(n=50) \text { Parameter }\end{array}$} & \multicolumn{2}{|l|}{ Range } & \multicolumn{2}{|c|}{ Mean \pm SD } & Mode \\
\hline & $1.15-3.61$ & \multicolumn{2}{|c|}{$2.42 \pm 0.58$} & 1.75 & \multicolumn{3}{|c|}{$\begin{array}{l}\text { Right breast/unshielded } \\
\text { (mGy) }\end{array}$} & \multicolumn{2}{|l|}{$3.65-8.50$} & \multicolumn{2}{|c|}{$5.38 \pm 2.11$} & 4.48 \\
\hline $\begin{array}{l}\text { Left breast/shielded } \\
\text { (mGy) }\end{array}$ & $1.02-2.40$ & \multicolumn{2}{|c|}{$1.35 \pm 0.33$} & 1.23 & \multicolumn{3}{|c|}{$\begin{array}{l}\text { Left breast/shielded } \\
\text { (mGy) }\end{array}$} & \multicolumn{2}{|c|}{$2.20-4.13$} & \multicolumn{2}{|c|}{$2.02 \pm 0.30$} & 1.82 \\
\hline Dose difference & \multicolumn{3}{|l|}{$2.61(72.3 \%)$} & & \multicolumn{3}{|c|}{ Dose difference } & \multicolumn{2}{|c|}{$4.37(51.4 \%)$} & \multirow{2}{*}{\multicolumn{2}{|c|}{$3.74 \pm 2.28$}} & \\
\hline Both breasts & $1.02-3.61$ & $1.94 \pm 0$ & 63 & 1.75 & \multicolumn{3}{|l|}{ Both breasts } & \multicolumn{2}{|c|}{$2.20-8.50$} & & & 4.48 \\
\hline Variables & $T$-statistics & $p$ value & Infe & rence & Variables & $T$-stati & istics & $p$ value & & \multicolumn{3}{|c|}{ Inference } \\
\hline \multicolumn{13}{|l|}{ Paired-sample $T$ test } \\
\hline $\begin{array}{l}\text { Right and left breast } \\
\text { dose }\end{array}$ & 10.593 & 0.001 & \multicolumn{2}{|c|}{$\begin{array}{l}\text { Significant relation- } \\
\text { ship exists }\end{array}$} & $\begin{array}{l}\text { Right and left breast } \\
\text { dose }\end{array}$ & \multicolumn{2}{|l|}{12.522} & 0.001 & & \multicolumn{3}{|c|}{$\begin{array}{l}\text { Significant relationship } \\
\text { exists }\end{array}$} \\
\hline Variables & $r$ & $p$ value & & Inference & Variables & & $r$ & & $p \mathrm{val}$ & lue & Infer & nce \\
\hline Pearson correlation of $\mathrm{d}$ & ose $(n=50)$ an & nd biometric & an & heters to test for & ature of relationship & & & & & & & \\
\hline $\begin{array}{l}\text { Left versus right } \\
\text { breasts }\end{array}$ & 0.313 & 0.015 & & $\begin{array}{l}=\text { mild } \\
D=\text { significant }\end{array}$ & Left versus right b & preasts & 0.202 & & 0.025 & & $\begin{array}{l}r=m \\
p=s\end{array}$ & $\begin{array}{l}d \\
\text { Inificant }\end{array}$ \\
\hline Dose versus age & 0.072 & 0.586 & & Weak & Age & & 0.110 & & 0.344 & & Weak & \\
\hline Dose versus weight & -0.012 & 0.927 & & Weak & Weight & & 0.052 & & $0.84 C$ & & Weak & \\
\hline Dose versus height & -0.034 & 0.796 & & Weak & Height & & -0.02 & & 0.690 & & Weak & \\
\hline Dose versus BMI & -0.021 & 0.872 & & Neak & BMI & & -0.10 & & 0.912 & & Weak & \\
\hline
\end{tabular}

mean dose of $1.35 \pm 0.33 / 2.42 \pm 0.58 \mathrm{mGy}(\mathrm{CR})$ and $2.02 \pm 0.30 / 5.38 \pm 2.11 \mathrm{mGy}(\mathrm{CT})$. Subsequent analysis using a paired-sample $T$ test revealed a statistically significant difference $(p=0.001)$ between the mean of shielded and unshielded breasts. That is an indication that shielding was practically useful. A further attempt at correlation returned weak relationship between dose and anthropometric parameters. The implication is that there are no evidence to suggest that body habitus influenced the emission of scattered radiation. That further necessitates the fact that shielding is important in addressing scatter irrespective of the size of the patient.

A closely similar and recent work from our country by Sidi et al. [6] corroborates our findings. They observed that scattered radiation from lumbosacral $\mathrm{x}$-ray as well as head CT got to the breasts. In lumbosacral $x$-ray, they got a mean dose of $1.74 \pm 0.40 / 2.30 \pm 0.50 \mathrm{mGy}$ for left (shielded) and right (unshielded) breast, respectively. The value was 3.00 $\pm 0.60 / 6.40 \pm 3.45 \mathrm{mGy}$ for CT. Also with $T$ test, they found a significant difference between the mean of both breasts. In another work with lumbosacral $\mathrm{x}$-ray carried out in Slovenia, Mekis et al. [5] observed as much as $80 \%$ reduction in breast dose when a $0.5 \mathrm{~mm}$ lead equivalent shielding material was used. A reduction of about $99 \%$ was reported in a work in United Arab Emirates [11]. Statistically significant dose reductions of $42 \%$ was also reported in a work published in America [12]. In CT of the head, postshielding dose reduction of about $62 \%$ was equally noted [10]. These strong and consistent evidences place a moral obligation on radiographers, especially in Africa, to adapt their practices to current imperatives.

Although some writers had a strong bias for dose optimization in preference to shielding and other dose reduction strategies [13, 14], we are of the opinion that it is of greater advantage if every known strategy is combined with shielding. Cancer, especially that of the breast, remains a scourge to sub-Saharan African women, and every effort that has some modicum of effectiveness in containing a carcinogen is important.

The major limitation of the work was the enormous distance between the dosimetric laboratory and our facility. That compelled the authors to send the TLDs for reading through courier. It was therefore difficult to determine if the courier company accorded our dosimeters the same extreme caution as we did. It would have been relieving to have a closer dosimetric laboratory where TLDs could be submitted ourselves without fear of extraneous or confounding variables. Notwithstanding, since our findings are in tandem with a large number of similar works, we are of the opinion that 
whatever error crept into our result is too small to negatively influence the results significantly.

\section{Conclusion}

In conclusion, machine and radiographer-specific strategies were unable to stop scatters from getting to the breast from head $\mathrm{x}$-ray and CT procedures. Also, breast shielding was found to significantly reduce dose from scatters. Adoption of shielding practice forthwith is strongly recommended.

\section{Abbreviations \\ ALARA: As low as reasonably achievable; CML: Canthomeatal line; CT: Computed tomography; CR: Computed radiography; kVp: Kilovolt peak; mA: Milliampere; MRI: Magnetic resonance imaging; PA: Postero-anterior; TLD: Thermoluminescent dosimeter.}

\section{Acknowledgements}

We acknowledge the cooperation of radiographers and radiologists in the facility who showed enormous goodwill for the work and demonstrated a high level of patience with the researchers even when clinical procedures were slowed down by researchers' presence.

\section{Authors' contributions}

All authors read and approved the final manuscript.

\section{Funding}

Not applicable.

\section{Availability of data and materials}

The data sets used and/or analysed during the current study are available from the corresponding author on reasonable request.

\section{Declarations}

\section{Ethics approval and consent to participate}

Ethical approvals were obtained from Research Ethics Committee of Nnamdi Azikiwe University Teaching Hospital, Nnewi, Nigeria (NAUTH/CS/66/NOL8/84/ and Radiography Department Ethics subcommittee of Gregory University, Uturu, Nigeria (GUU/RAD/ECNOL3/002.

\section{Consent for publication}

Not applicable.

\section{Competing interests}

The authors declare that they have no competing interests.

\section{Author details}

'Department of Radiography, Federal University of Technology, Owerri, Nigeria. ${ }^{2}$ Department of Radiography and Radiological Sciences, Nnamdi Azikiwe University, Awka, Nnewi Campus, Nigeria. ${ }^{3}$ Department of Radiography and Radiation Sciences, Gregory University, Uturu, Abia State, Nigeria. ${ }^{4}$ Department of Radiography and Radiological Sciences, University of Nigeria, Nsukka, Enugu Campus, Nigeria.
Received: 10 June 2021 Accepted: 10 September 2021

Published online: 28 September 2021

\section{References}

1. Adejoh T, Elugwu CH, Sidi M, Ezugwu EE, Asogwa CO, Okeji MC (2020) An audit of radiographers' practice of left-right image annotation in filmscreen radiography and after installation of computed radiography in a tertiary hospital in Africa. Egypt J Radiol Nucl Med 51:66-70

2. Omondi SO, Msaki PK, Ramadhan KR, Lugendo IJ (2020) Improved image quality in digital mammography using anti-scatter grids. Tanzania J Sci 46(3):620-627

3. Cumber SN, Nchanji KN, Tsoka-Gwegweni JM (2017) Breast cancer among women in Sub-Saharan Africa: prevalence and situational analysis. S Afr J Gynaecol Oncol 9:35-37

4. Owusu-Banahene J, Darko EO, Charles DF, Maruf A, Hanan I, Amoako G (2018) Scatter radiation dose assessment in the Radiology Department of Cape Coast Teaching Hospital-Ghana. Open J Radiol 8:299-306. https:// doi.org/10.4236/ojrad.2018.84033

5. Mekis N, Zontar D, Skrk D (2013) The effect of breast shielding during lumbar spine radiography. Radiol Oncol 47(1):26-31

6. Sidi M, Elugwu CH (2020) Quantification of scattered radiation to adult female breasts during lumbosacral X-ray and head computed tomography in a Negroid population. Pak J Radiol 30(4):252-256

7. Okeji MC, Anakwue AC, Agwuna K (2010) Radiation exposure from diagnostic radiography: an assessment of $X$-ray beam collimation practice in some Nigerian Hospitals. Internet J Med Update 5(2):31-33

8. Abdulkadir MK, Piersson AD, Musa GM, Audu SA, Abubakar A, Muftaudeen B, Umana JE (2021) Assessment of diagnostic reference levels awareness and knowledge amongst CT radiographers. Egypt J Radiol Nucl Med 52:67-73. https://doi.org/10.1186/s43055-021-00444-x

9. Gunn ML, Kanal KM, Kolokythas O, Anzal Y (2009) Radiation dose to the thyroid gland and breast from mutidetector computed tomography of the cervical spine: does bismuth shielding with and without a cervical collar reduce dose? J Comput Assist Tomogr 33(6):987-990

10. Brnic Z, Vekic B, Hebrang A, Anic P (2003) Efficacy of breast shielding during CT of the head. Eur Radiol 13(11):2436-2440

11. Elshami W, Abuzaid MM, Tekin HO (2020) Effectiveness of breast and eye shielding during cervical spine radiography: an experimental study. Risk Manag Healthc Policy 13:697-704. https://doi.org/10.2147/RMHP.S2571 85

12. Revel M-P, Fitton I, Audureau E, Benzakoun J, Lederlin M, Chabi M-L, Rousset $P$ (2015) Breast dose reduction options during thoracic CT: influence of breast thickness. Am J Roentgenol 204:W421-W428

13. Collenti MC, Micheli OA, Lee KH (2013) To shield or not to shield: application of bismuth breast shields. Am J Roentgenol 200:503-507. https://doi. org/10.2214/AJR.12.9997

14. McCollough CH, Wang J, Gould RG, Orton CG (2012) The use of bismuth breast shields for CT should be discouraged. Med Phys 39(5):2321-2324. https://doi.org/10.1118/1.3681014

\section{Publisher's Note}

Springer Nature remains neutral with regard to jurisdictional claims in published maps and institutional affiliations. 